\title{
Association of Practices Regarding Infant and Young Child Feeding with Anthropometry Measurements Among an Urban Population in Karnataka, India
}

Bhanuja Bhagwat ${ }^{1}$, Shalini Chandrashekar Nooyi ${ }^{1}$, Dinesh H. Krishnareddy ${ }^{1}$, Srinivasa Nandagudi Murthy 1

1. Department of Community Medicine, M S Ramaiah Medical College, Bangalore, IND

Corresponding author: Bhanuja Bhagwat, bhagwatbhanuja@gmail.com

\section{Abstract}

\section{Background}

Mothers' knowledge of infant and young child feeding (IYCF) play a crucial role in the overall growth and development of a child, determined by their anthropometry. Malnutrition has been linked to the short- and long-term effects on child health and, ultimately, national development. This community-based crosssectional study focuses on the nutritional parameters of infants and young children in an urban slum population. The primary objective was to study IYCF from birth up to two years of age. The secondary objective involved studying the association between feeding practices and anthropometric measurements among children of 12-23 months of age.

\section{Methods}

The mothers of 96 children who were between 12 and 23 months of age, living in the urban slum of B.K Nagar, Bangalore, India, were administered the United Nations Children's Fund (UNICEF) IYCF questionnaire. Breastfeeding and complementary feeding information from these children from birth to 24 months were obtained. Anthropometric measurements were measured with appropriate calibrations.

\section{Results}

The population consisted of $57.3 \%$ females and $42.7 \%$ males. All children had mean anthropometric measurements below the World Health Organization Multicentre Growth Reference Study (WHO-MGRS) standard (weight for age in males, $\mathrm{P}=0.009$, and females $\mathrm{P}=0.005$ ). A delay in the initiation of breastfeeding was observed in female children (54.5\%), showing a significant reduction in their weight $(\mathrm{P}=0.020)$ as compared to those initiated early. There was also a declining trend of continuation of breastfeeding from age 12 months to 23 months. The study revealed a high consumption of gripe water (68.8\%) and bottle feeding (40.4\%). A significant difference was found in children who consumed nutritious food, especially meat, with

Received 02/22/2019

Review began 03/04/2019 Review ended 03/26/2019 Published 03/29/2019

\section{๑) Copyright 2019}

Bhagwat et al. This is an open access article distributed under the terms of the Creative Commons Attribution License CC-BY 3.0., which permits unrestricted use, distribution, and reproduction in any medium, provided the original author and source are credited. height $(\mathrm{P}=0.018)$ and weight $(\mathrm{P}=0.011)$, along with other foods.

\section{Conclusion}

IYCF and anthropometry have a direct association, evidence of which is reflected by the mother's knowledge of feeding practices along with other socioeconomic parameters.

Categories: Pediatrics, Preventive Medicine, Public Health

Keywords: anthropometry, community, complementary feeding, gripe water, iycf, urban slum, initiation of breastfeeding, mgrs, continued breastfeeding, nfhs

\section{Introduction}

The health outcomes of a child are directly proportional to their feeding practices, which are, in turn, dependent on the knowledge and practices of the mother. The first two years of a child's life are crucial to ensure appropriate growth and development. Malnutrition during this period results in a series of problems, beginning with reduced weight for age and stunting, progressing to the inability to achieve potential height in adulthood, and reduced capacity for physical work, which ultimately has implications for national development [1]. Improper feeding practices have also been linked to reduced reproductive capacity, complicated deliveries, and increased incidence of low birth weight infants in women who were malnourished as children [2].

The World Health Organization (WHO) has defined certain indicators to effectively assess infant and young child feeding practices. They are: early initiation of breastfeeding, exclusive breastfeeding under six months of age, continued breastfeeding at one year and at two years [3]. However, breastfeeding rates continue to be 
low worldwide, especially in high-income countries, where just one in five infants is breastfed [4]. A recent study analyzing the global trends on breastfeeding showed that the prevalence of exclusive breastfeeding among infants younger than six months in developing countries increased from 33\% in 1995 to 39\% in 2010 but has still not reached the target of at least 50\% [5-6].

The National Family Health Survey (NFHS) of India is a multi-round survey conducted in a representative sample of households throughout the nation. The latest report of 2015-2016 (NFHS-4, India Fact Sheet) has determined that only $42.8 \%$ of urban neonates were given breast milk within one hour of birth and $52.1 \%$ urban infants were exclusively breastfed up to six months of age. It has also stated that the total number of urban children aged six to 23 months receiving an adequate diet is merely $11.6 \%$ [7].

Studies have been conducted to demonstrate the long-term effects of breastfeeding, with its impact on intelligence quotient (IQ) and prevention of diseases such as hypertension, type two diabetes mellitus, and even problems related to obesity [8-9]. It has also been shown to reduce the risk of pneumonia mortality and morbidity in young children [10].

This study was conducted to establish evidence of the association of infant and young child feeding (IYCF) with anthropometric measurements in an urban slum in Bangalore using the IYCF module by the United Nations Children's Fund (UNICEF). Anthropometry measurements are simple and effective indicators of nutritional status and, hence, the adequacy of feeding practices.

Our primary objective was to study the feeding practices of infants and children from birth up to two years of age and the secondary objective was to study the association between feeding practices and anthropometric measurements among children of 12-23 months of age.

\section{Materials And Methods}

A community- based, cross-sectional study was conducted in April and May 2017 on mothers of 96 children who were between 12 and 23 months of age and who live in the urban slum setting of B.K. Nagar, Bangalore, Karnataka, India. This urban slum is part of the field practice area of MS Ramaiah Medical College, Bangalore, India. B.K. Nagar caters to a population of 96,000 and this area has been divided into census enumeration blocks (CEB) as per the government of India. Five such CEB were chosen at random and an orderly house-to-house survey was conducted. Mothers of children between 12 and 23 months of age were included as study subjects. Breastfeeding and complementary feeding information from these children from birth to 24 months was collected. Adopted children or children whose mothers were deceased were excluded.

\section{Sample size}

Based on the data from the latest report of NFHS-4 (2015-2016) results in India, which was obtained by multiple government field agencies that surveyed over 600,000 households, the expected proportion of urban neonates that were given breast milk within one hour of birth being $42.8 \%$ with an absolute precision of $10 \%$ and a confidence level of $95 \%$, the required sample size was 94 . This sample size was also adequate to study the second objective since children below five years of age and were stunted were $32.6 \%$ and those underweight for age were $31.5 \%$ according to NFHS-4 [7]. The 'N MASTER 2.0 software' (designed and developed by Biostatistics Resource and Training Centre, Christian Medical College, Vellore, India) was used to determine the above-mentioned sample size.

Permission to conduct the study was obtained from the institutional ethics board. On approval, informed consent was obtained from the study subjects explaining in detail about this research.

\section{Study tool}

The World Health Organisation has recently published a module titled "Indicators for assessing infant and young child feeding (IYCF) practices," which contains a questionnaire that was adapted to suit our study and helped us understand these practices [11]. The questionnaire begins with a household roster and other sociodemographic data to determine those subjects who are eligible for the questionnaire. The socioeconomic status for each family was calculated using the modified Kuppuswamy classification that was updated for 2017 with respect to income criteria [12]. The next section is the "initiation of breastfeeding module" which was administered to mothers of children aged 12-23 months. This was followed by the "infant and young child feeding module" which consists of questions regarding age, birth registration, and breastfeeding and complementary feeding details. After establishing a close rapport, a house to house survey was conducted per the recommendations of the IYCF module. The first and third author conducted the interview upon translating questions to the local language. Recall bias was minimized in the form of rephrasing questions to obtain consistency in responses.

Anthropometric measurements included weight, height, mid-upper arm circumference (MUAC), and head circumference (HC). Weight was documented using a weighing balance that was carried to the site (calibrated with a known weight every day) and measured to the nearest $0.5 \mathrm{kgs}$. Height was measured by making the child stand straight up on a leveled surface against the wall against a non-stretchable 
measuring tape. The MUAC was measured with a non-stretchable tape at a midpoint between the acromion and olecranon process of the non-dominant arm kept relaxed by the side of the body. HC was measured by placing the tape around the head over the glabella anteriorly and the occiput posteriorly by the overlap method. All parameters were measured to the nearest $0.5 \mathrm{~cm}$.

\section{Statistical analysis}

Quantitative variables, such as age and anthropometric measurements, were analyzed using descriptive statistics such as mean and standard deviation. Qualitative variables, such as gender, infant breastfeeding, and supplementary feeding practices, were analyzed using frequencies, percentages, and the association of feeding practices with anthropometry was determined using percentages, $\mathrm{Z}$ scores, along with a 95\% confidence interval. Tests used to determine significance were the student's t-test, $\mathrm{Z}$ test (since the data followed a normal distribution), and chi-square test. Additionally, odds ratio (OR) was calculated to compare various food items with anthropometric data. The SPSS-18.0 software (SPSS Inc. Released 2009. PASW Statistics for Windows, Version 18.0. Chicago: SPSS Inc.) was used for basic statistical analysis.

In order to understand and compare the anthropometric data of this study population, the WHO Multicenter Growth Reference Study (MGRS) [13] was utilized as a standard of comparison. Additionally, WHO Anthro (Version 3.2.2, January 2011) was used to analyze these anthropometric parameters and generate graphs, which uses the MGRS data as a standard of comparison.

\section{Results}

In this study, among 738 houses in five CEBs in the B.K. Nagar urban slum area, the first consecutive 94 households ( 96 children) that met the criteria were interviewed. It was found that there were 41 male children (42.7\%) and 55 female children (57.3\%), with more number of children in the age group of 21 to 23 completed months (28.1\%). However, it was observed that the percentage of children in different age groups based on gender was not statistically significant $(\mathrm{p}=0.087$ ). It was also found that the majority of the children were from a nuclear family and belonged to the upper lower socioeconomic group as shown in Table 1. 


\section{Cureus}

\begin{tabular}{|c|c|c|c|}
\hline Socio-demographic characteristics & Males & Females & p-value \\
\hline \multicolumn{4}{|l|}{ Age in months } \\
\hline $12-14$ & $12(29.3 \%)$ & $9(16.4 \%)$ & \\
\hline 15-17 & $8(19.5 \%)$ & $8(14.5 \%)$ & \\
\hline $18-20$ & $8(19.5 \%)$ & $24(43.6 \%)$ & \\
\hline $21-23$ & $13(31.7 \%)$ & $14(25.5 \%)$ & \\
\hline Total & $41(100 \%)$ & $55(100 \%)$ & 0.087 \\
\hline \multicolumn{4}{|l|}{ Type of family } \\
\hline Nuclear & $28(68.3 \%)$ & $34(61.8 \%)$ & \\
\hline Joint & $6(14.6 \%)$ & $9(16.4 \%)$ & \\
\hline Three generation & 7 (17.1\%) & $12(21.8 \%)$ & \\
\hline Total & $41(100 \%)$ & $55(100 \%)$ & 0.793 \\
\hline \multicolumn{4}{|l|}{ Socioeconomic Status $\{12\}$} \\
\hline Upper & $4(9.8 \%)$ & 2 (3.6\%) & \\
\hline Upper middle & $12(29.3 \%)$ & $14(25.5 \%)$ & \\
\hline Lower middle & $8(19.5 \%)$ & $15(27.3 \%)$ & \\
\hline Upper lower & $17(41.5 \%)$ & $21(38.2 \%)$ & \\
\hline Lower & $0(0 \%)$ & $3(5.5 \%)$ & \\
\hline Total & $41(100 \%)$ & $55(100 \%)$ & 0.519 \\
\hline \multicolumn{4}{|l|}{ Maternal Education } \\
\hline Up to Middle School & 9 (69.2\%) & $4(30.8 \%)$ & \\
\hline High School & 19 (32.8\%) & $39(67.2 \%)$ & \\
\hline Above High School & $13(52.0 \%)$ & $12(48.0 \%)$ & \\
\hline Total & $41(100 \%)$ & $55(100 \%)$ & $0.031^{*}$ \\
\hline \multicolumn{4}{|l|}{ Maternal occupation } \\
\hline Housewife & $33(80.5 \%)$ & $50(90.9 \%)$ & \\
\hline Employed & $8(61.5 \%)$ & 5 (38.5\%) & \\
\hline Total & $41(100 \%)$ & 55 (100\%) & 0.140 \\
\hline
\end{tabular}

\section{TABLE 1: Socio-demographic characteristics (total males $=41$, total females $=55, N=96$ )}

*: indicates values that are statistically significant

The mean anthropometric measurements of the study population are shown in Table 2. A difference in weight, height, and HC between males and females, notably in the age group of $21-23$ months ( $\mathrm{p}=0.006$, $\mathrm{p}=0.047, \mathrm{p}=0.001$ ) were found to be significant. Anthropometric measurements in the study group and the WHO-MGRS standard with respect to gender was plotted graphically. It was observed that in the study population, the mean $\mathrm{Z}$ scores of $30 \%$ females $(\mathrm{p}=0.005)$ and $28 \%$ males $(\mathrm{p}=0.009)$ for weight for age (Figure 1), $24 \%$ females $(p=0.006)$, and $27 \%$ males $(p=0.061)$ for height for age (Figure 2 ) were lower than the mean $Z$ scores of the WHO population, which was $40 \%$. It was also found that $26 \%$ females $(\mathrm{p}=0.018$ ) and $45 \%$ males $(\mathrm{p}=0.589)$ for HC for age (Figure 3$)$ and $32 \%$ females $(\mathrm{p}=0.204)$ and $36 \%$ males $(\mathrm{p}=0.596)$ for MUAC for age (Figure 4) also followed the same trend. WHO Anthro was used to analyze the basic indicators of malnutrition and the cut-off for each indicator was considered to be below -2 SD. It was observed that out of the total population, $16.7 \%$ (males $=9.8 \%$, females $=21.8 \%$ ) were wasted, out of which $4.2 \%$ (males $2.4 \%$, females $=5.5 \%$ ) were severely wasted (below $-3 \mathrm{SD}$ ), $50 \%$ (males $=56.1 \%$, females $=45.5 \%$ ) stunted and $26 \%$ 


\section{Cureus}

$($ males $=14.6 \%$, females $=34.5 \%)$ underweight .

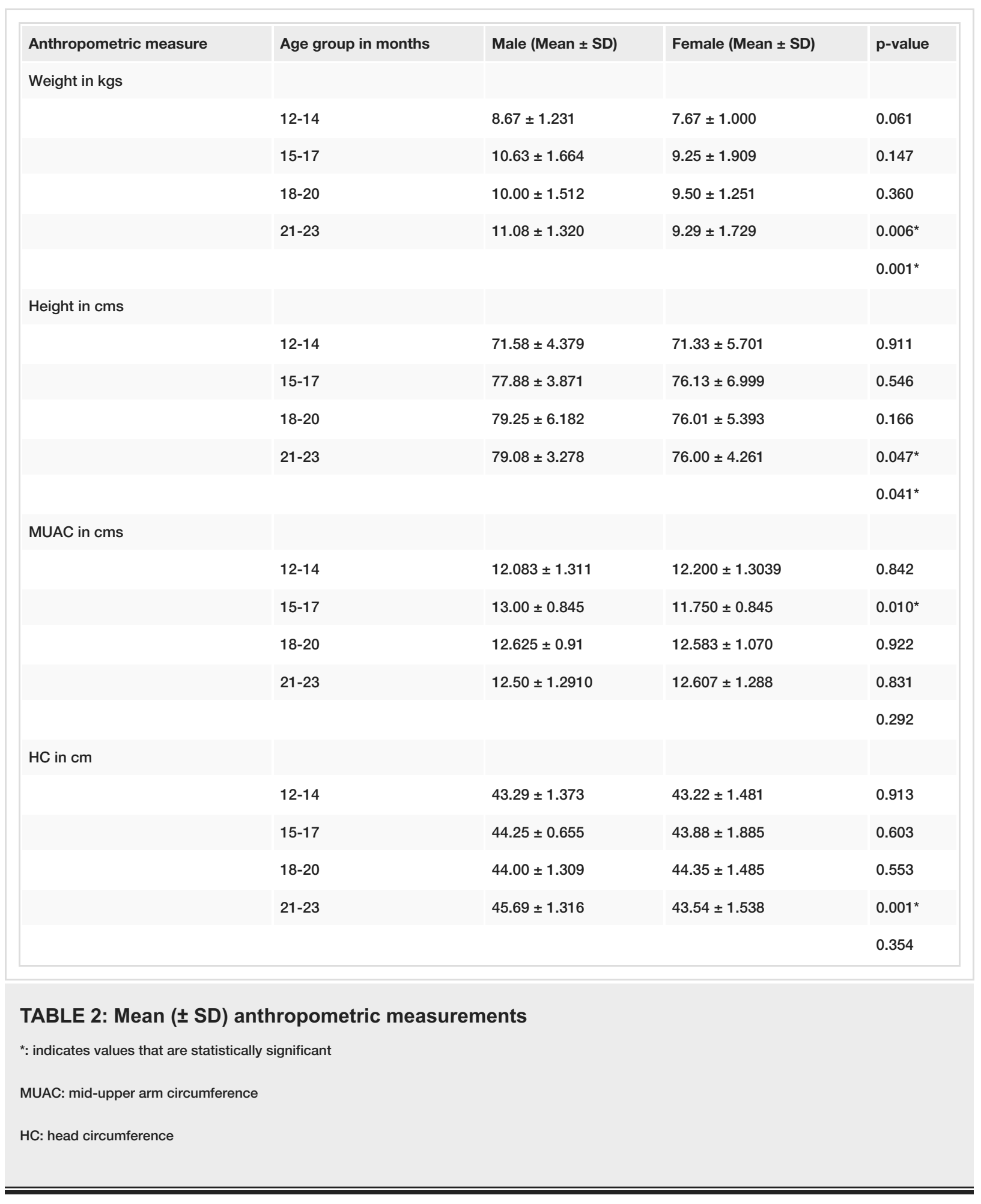




\section{Cureus}

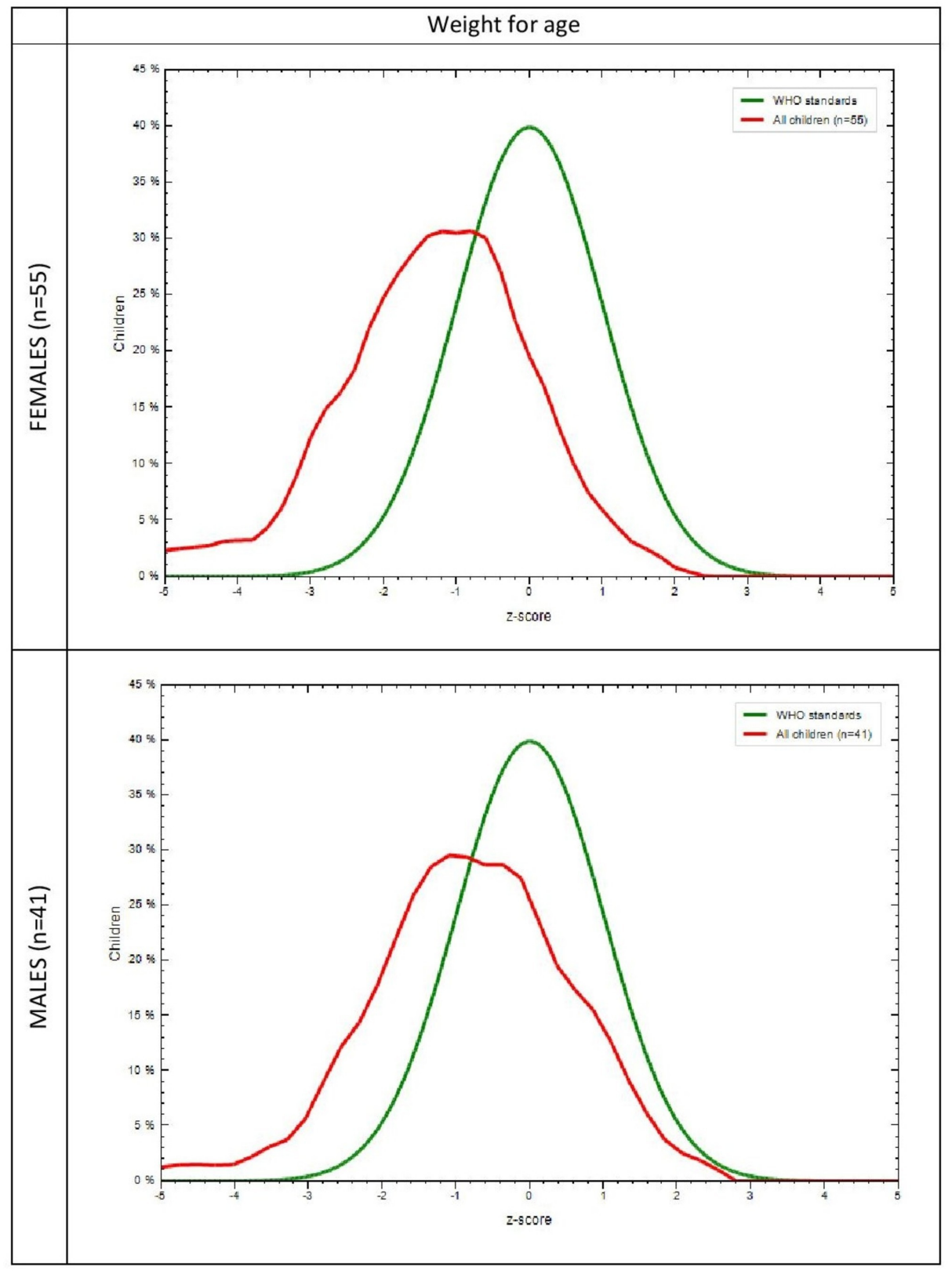

FIGURE 1: Comparison of weight for age in the study group and the WHO-MGRS standard by gender

WHO-MGRS: World Health Organization Multicenter Growth Reference Study

X-axis represents $\mathrm{z}$ scores

Y-axis represents \% of children

Green curve represents the WHO standard

Red curve represents the study population 


\section{Cureus}

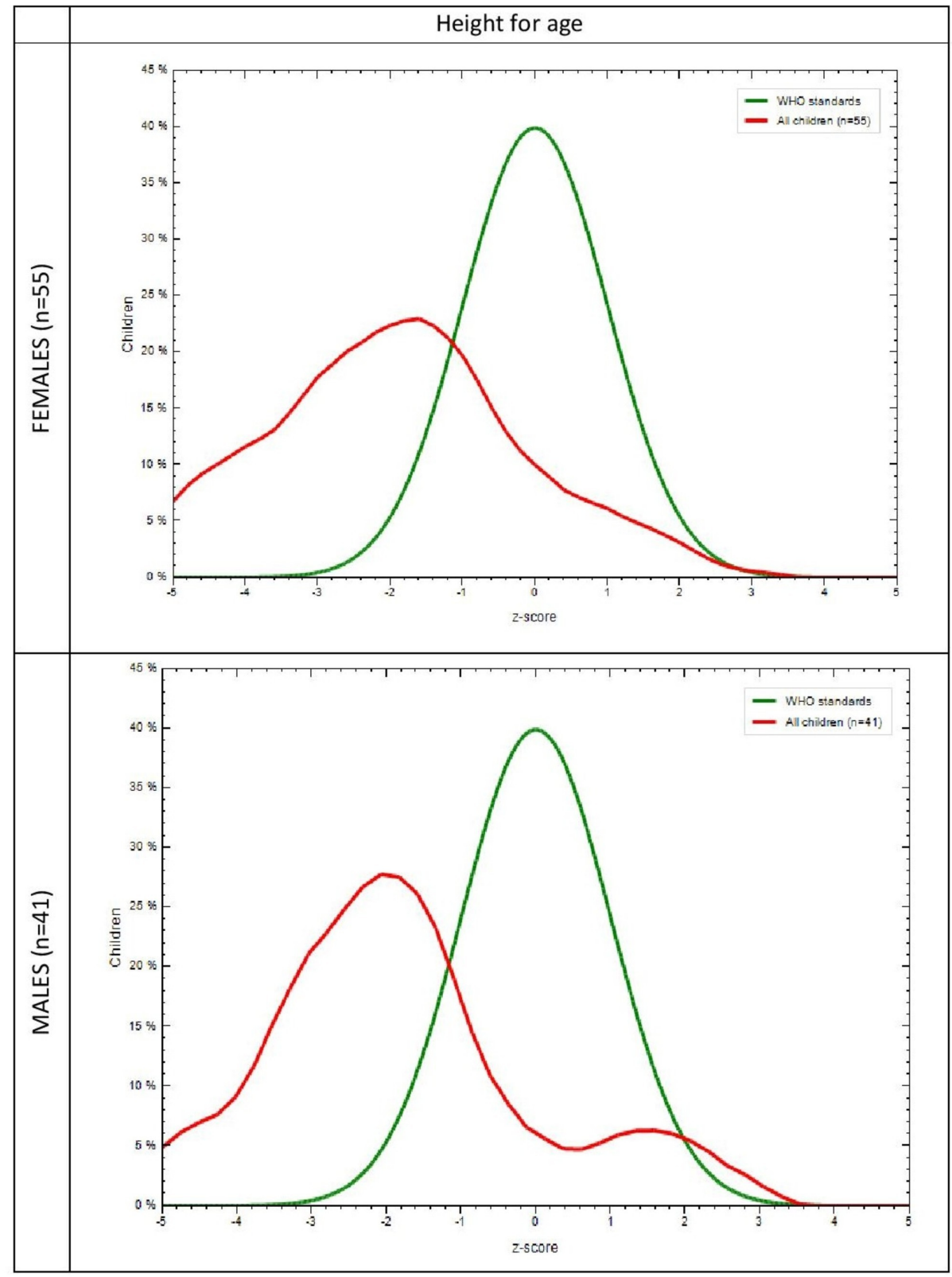

FIGURE 2: Comparison of height for age in the study group and the WHO-MGRS standard by gender

WHO-MGRS: World Health Organization Multicenter Growth Reference Study

$\mathrm{X}$-axis represents $\mathrm{z}$ scores

Y-axis represents $\%$ of children

Green curve represents the WHO standard

Red curve represents the study population 


\section{Cureus}

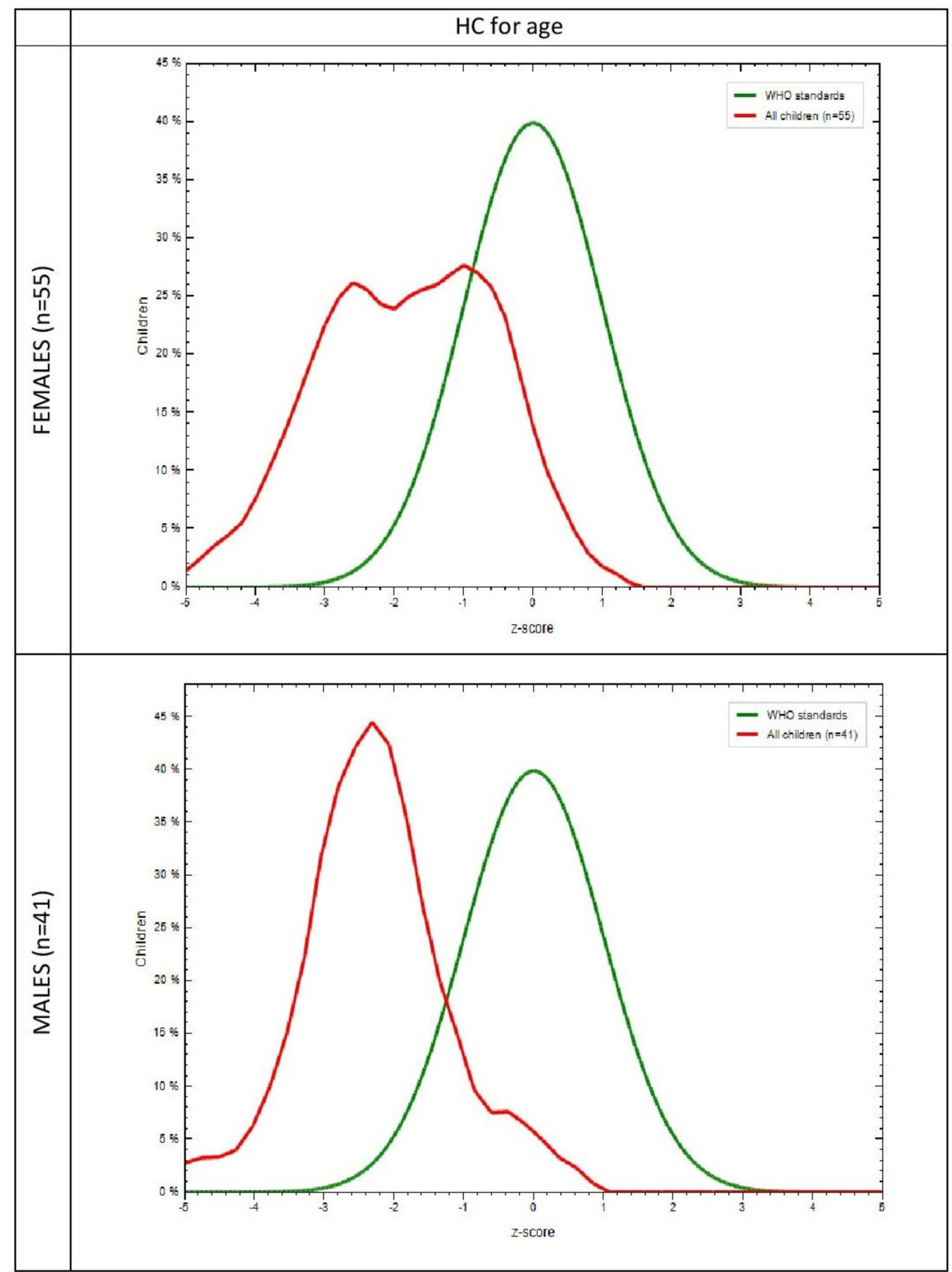

FIGURE 3: Comparison of head circumference for age in the study group and the WHO-MGRS standard by gender

WHO-MGRS: World Health Organization Multicenter Growth Reference Study; HC: Head circumference

X-axis represents z scores

Y-axis represents \% of children

Green curve represents the WHO standard

Red curve represents the study population 


\section{Cureus}

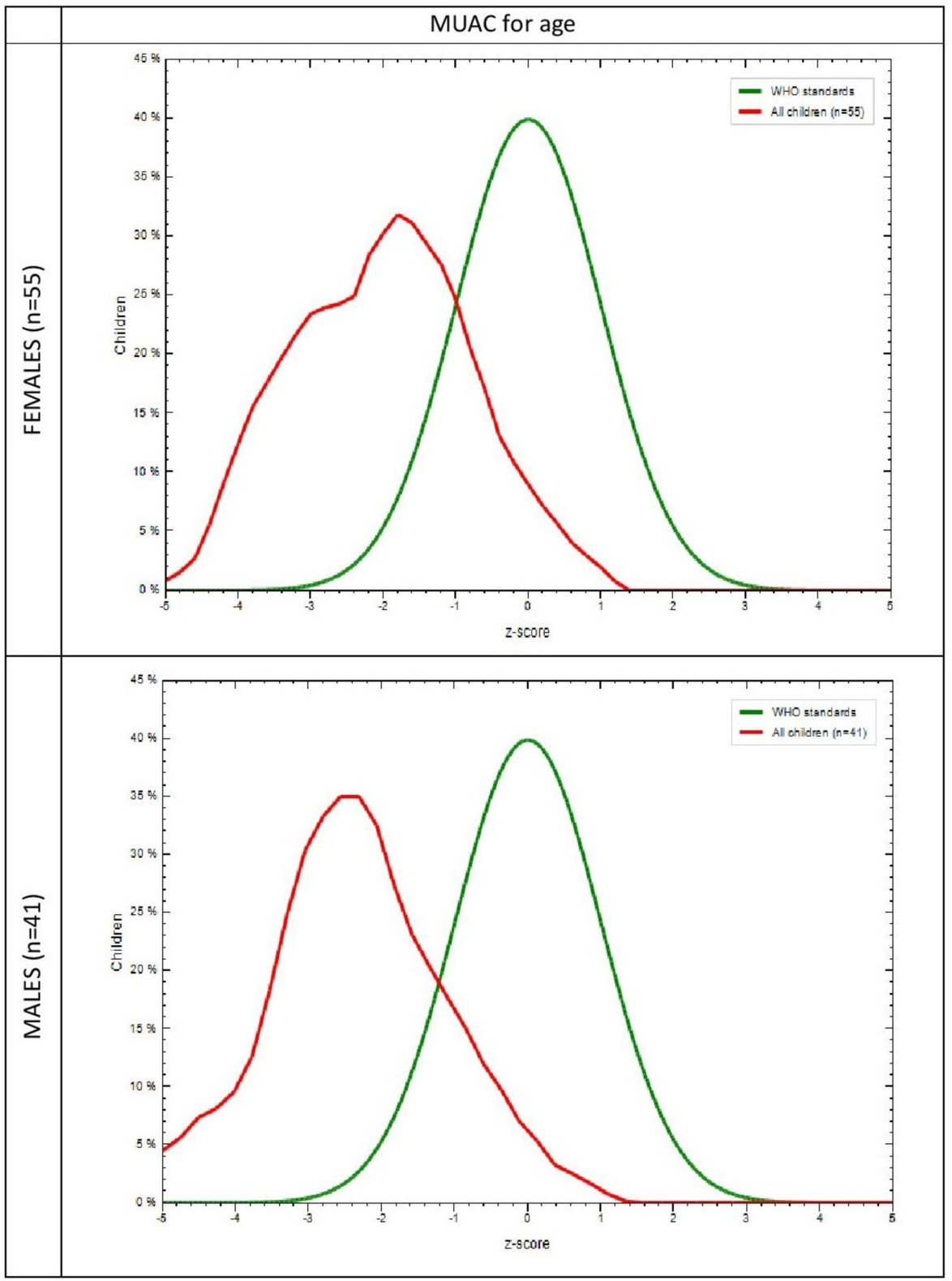

FIGURE 4: Comparison of mid-upper arm circumference for age in the study group and the WHO-MGRS standard by gender

MUAC: Mid-upper arm circumference; WHO-MGRS: World Health Organization Multicenter Growth Reference Study

$\mathrm{X}$-axis represents $\mathrm{z}$ scores

Y-axis represents \% of children

Green curve represents the WHO standard

Red curve represents the study population

Initiation of breastfeeding is recommended as soon as the mothers give birth [1]. Early initiation of breastfeeding is important; however, certain circumstances may limit the accessibility of a child to breast milk due to various reasons (Table 3). Irrespective of the method of delivery, initiation of breastfeeding up to one hour was considered as not delayed. On analysis of the children's feeding practices, it was found that the delay in breastfeeding was more in female children (54.5\%) as compared to male children (43.9\%) with the most common reason being a delay in initiation after a cesarean section (Table 3). It was also observed that $3.6 \%$ of the female children were not initiated with breast milk early due to religious reasons. A 


\section{Cureus}

comparison of mean anthropometric measurements amongst the "delayed" and "not delayed" revealed that there was a significant reduction in weight among females in whom breastfeeding was delayed $(\mathrm{p}=0.020)$ (Table 4). In terms of continuity of breastfeeding, it was found that at age 12 months $84.6 \%$, at 18 months $50 \%$, and at 23 months only $14.3 \%$ of children were given breast milk along with complementary foods.

\begin{tabular}{|c|c|c|c|c|}
\hline Initiation of Breastfeeding & & Males & Females & P value \\
\hline \multirow[t]{2}{*}{ Delayed } & $1-3$ hours & $9(50 \%)$ & $21(70 \%)$ & \\
\hline & $>3$ hours & $9(50 \%)$ & $9(30 \%)$ & \\
\hline Total & & 18(43.9\%) & 30 (54.5\%) & 0.106 \\
\hline Not delayed & & $23(56.1 \%)$ & 25 (45.5\%) & \\
\hline Total & & $41(100 \%)$ & $55(100 \%)$ & 0.302 \\
\hline \multicolumn{5}{|l|}{ Reasons for delay } \\
\hline C section & & $9(22.0 \%)$ & $14(25.5 \%)$ & \\
\hline No milk production & & $4(9.8 \%)$ & $5(9.1 \%)$ & \\
\hline PPH postoperative complications & & $1(2.4 \%)$ & $3(5.5 \%)$ & \\
\hline NICU admission of child & & $2(4.9 \%)$ & $1(1.8 \%)$ & \\
\hline Religious reasons & & $0(0 \%)$ & 2 (3.6\%) & \\
\hline Feeding issues with child & & $2(4.9 \%)$ & $0(0 \%)$ & \\
\hline No specific reason/Don't know & & $0(0 \%)$ & $5(9.1 \%)$ & \\
\hline Total & & $18(100 \%)$ & $30(100 \%)$ & 0.201 \\
\hline
\end{tabular}

\section{TABLE 3: Breastfeeding practices and reasons for delay}

*: indicates values that are statistically significant

PPH: Post-partum hemorrhage

NICU: Neonatal intensive care unit

\begin{tabular}{|c|c|c|c|c|c|c|}
\hline \multirow{2}{*}{ Anthropometry } & \multicolumn{3}{|l|}{ Males } & \multicolumn{3}{|l|}{ Females } \\
\hline & Delayed & Not delayed & $P$ value & Delayed & Not delayed & $P$ value \\
\hline Weight in kgs & $9.72 \pm 1.555$ & $10.35 \pm 1.748$ & 0.240 & $8.67 \pm 1.729$ & $9.64 \pm 1.150$ & $0.020^{*}$ \\
\hline Height in $\mathrm{cm}$ & $77.22 \pm 5.440$ & $76.26 \pm 5.437$ & 0.578 & $74.71 \pm 5.445$ & $75.92 \pm 5.751$ & 0.426 \\
\hline MUAC in $\mathrm{cm}$ & $12.556 \pm 1.069$ & $12.457 \pm 1.251$ & 0.099 & $12.450 \pm 1.241$ & $12.352 \pm 1.0576$ & 0.757 \\
\hline $\mathrm{HC}$ in $\mathrm{cm}$ & $44.58 \pm 1.478$ & $44.22 \pm 1.594$ & 0.366 & $43.63 \pm 1.727$ & $44.20 \pm 1.354$ & 0.188 \\
\hline
\end{tabular}

\section{TABLE 4: Mean anthropometry by initiation of breastfeeding}

*: indicates values that are statistically significant

MUAC: Mid-upper arm circumference

HC: Head circumference

The IYCF questionnaire includes details of complementary feeds given to the child, though it does not include the quantity of food consumed and age of initiation. Food items were analyzed in terms of liquids and semisolids consumed and the results were as follows. Among liquids, $15.6 \%$ of the study group 


\section{Cureus}

consumed formula feeds and $94.8 \%$ of the population consumed buffalo's/cow's milk with $69.8 \%$ consumption of other dairy products. Other liquids consumed included fruit juices (70.8\%), gripe water (68.8\%), oral rehydration salts (17.7\%), and vitamin drops (13.5\%). Among semisolid food items, cereals, roots, tubers, fruits, and vegetables were consumed by all children. It was found that $86.5 \%$ of the study population were non-vegetarians (including egg) and 13.5\% were pure vegetarians. Among the nonvegetarians, the percentage of consumption was as follows: organ meat $24.0 \%$, meats $64.6 \%$, eggs $81.3 \%$, and seafood $53.1 \%$. Foods rich in vitamin A were consumed by $93.8 \%$ of the population. The percentage consumption of oils was $74 \%$ and that of sugary food and condiments were $93.8 \%$ and $64.6 \%$, respectively. On detailed questioning of feeding practices, it was observed that $40.6 \%$ of the study population provided bottle feeds to their children, with the rate of bottle feeding increasing from $23.8 \%$ at $12-14$ months to $51.9 \%$ at $21-23$ months.

Comparison of mean anthropometric measurements of those consuming a particular food item and those who did not were made. Though all measurements and food items were analyzed, a significant difference was found only with weight and height among those who consumed meat, eggs, seafood, sugary food, gripe water, thin porridge, and clear broth, as shown in Tables 5-6. The differences in HC and MUAC among study population who consumed the above-mentioned food items were not found to be statistically significant. There was also no statistical difference among those who consumed cereals, grains, foods rich in vitamin A, fruits, green leafy vegetables, roots, tubers, and milk products.

\begin{tabular}{|c|c|c|c|c|c|c|c|}
\hline \multirow[b]{2}{*}{ Complementary food } & \multirow[b]{2}{*}{ Consumption } & \multicolumn{2}{|c|}{ Total population $(n=96)$} & \multicolumn{2}{|l|}{ Males $(n=41)$} & \multicolumn{2}{|l|}{ Females $(n=55)$} \\
\hline & & Mean \pm SD & p-value & Mean \pm SD & p-value & Mean \pm SD & p-value \\
\hline \multirow[t]{2}{*}{ Meat } & Consumed & $9.84 \pm 1.642$ & \multirow{2}{*}{$0.011^{*}$} & $10.67 \pm 1.711$ & \multirow{2}{*}{$0.005^{\star}$} & $9.32 \pm 1.378$ & \multirow{2}{*}{0.143} \\
\hline & Not consumed & $8.94 \pm 1.590$ & & $9.24 \pm 1.239$ & & $8.65 \pm 1.869$ & \\
\hline \multirow[t]{2}{*}{ Eggs } & Consumed & $9.73 \pm 1.678$ & \multirow{2}{*}{$0.010^{*}$} & $10.27 \pm 1.750$ & \multirow{2}{*}{0.123} & $9.33 \pm 1.523$ & \multirow{2}{*}{$0.022^{*}$} \\
\hline & Not consumed & $8.61 \pm 1.335$ & & $9.25 \pm 1.035$ & & $8.10 \pm 1.370$ & \\
\hline \multirow[t]{2}{*}{ Seafood } & Consumed & $9.84 \pm 1.602$ & \multirow{2}{*}{$0.044^{*}$} & $10.20 \pm 1.601$ & \multirow{2}{*}{0.642} & $9.61 \pm 1.585$ & \multirow{2}{*}{$0.005^{\star}$} \\
\hline & Not consumed & $9.16 \pm 1.692$ & & $9.95 \pm 1.774$ & & $8.46 \pm 1.285$ & \\
\hline \multirow[t]{2}{*}{ Sugary food } & Consumed & $9.48 \pm 1.656$ & \multirow{2}{*}{0.331} & $10.13 \pm 1.737$ & \multirow{2}{*}{0.360} & $8.98 \pm 1.503$ & \multirow{2}{*}{$0.027^{\star}$} \\
\hline & Not consumed & $10.17 \pm 1.941$ & & $9.00 \pm 2.828$ & & $10.75 \pm 1.500$ & \\
\hline \multirow[t]{2}{*}{ Gripe water } & Consumed & $9.74 \pm 1.542$ & \multirow{2}{*}{$0.054^{*}$} & $10.13 \pm 1.737$ & \multirow{2}{*}{0.714} & $9.38 \pm 1.256$ & \multirow{2}{*}{0.099} \\
\hline & Not consumed & $9.03 \pm 1.861$ & & $9.89 \pm 1.516$ & & $8.67 \pm 1.906$ & \\
\hline \multirow[t]{2}{*}{ Thin porridge } & Consumed & $8.81 \pm 1.358$ & \multirow{2}{*}{$0.000^{*}$} & $9.35 \pm 1.101$ & \multirow{2}{*}{$0.019^{*}$} & $8.50 \pm 1.408$ & \multirow{2}{*}{$0.001^{*}$} \\
\hline & Not consumed & $10.20 \pm 1.671$ & & $10.58 \pm 1.840$ & & $9.84 \pm 1.438$ & \\
\hline \multirow[t]{2}{*}{ Clear broth } & Consumed & $9.49 \pm 1.683$ & \multirow{2}{*}{0.330} & $10.00 \pm 1.711$ & \multirow{2}{*}{0.506} & $9.13 \pm 1.579$ & \multirow{2}{*}{0.845} \\
\hline & Not consumed & $9.69 \pm 1.653$ & & $10.50 \pm 1.517$ & & $9.00 \pm 1.528$ & \\
\hline
\end{tabular}

TABLE 5: Mean (ISD) weight (in kg) of children aged 12-23 months based on consumption of each food item

*: indicates values that are statistically significant 


\begin{tabular}{|c|c|c|c|c|c|c|c|}
\hline \multirow[b]{2}{*}{ Complimentary food } & \multirow[b]{2}{*}{ Consumption } & \multicolumn{2}{|c|}{ Total population $(n=96)$} & \multicolumn{2}{|l|}{ Males $(n=41)$} & \multicolumn{2}{|l|}{ Females $(n=55)$} \\
\hline & & Mean \pm SD & $P$ value & Mean \pm SD & $\mathrm{p}$-value & Mean \pm SD & $P$ value \\
\hline \multirow[t]{2}{*}{ Meat } & Consumed & $74.84 \pm 5.068$ & \multirow{2}{*}{$0.018^{*}$} & $77.75 \pm 5.447$ & \multirow{2}{*}{0.134} & $76.27 \pm 4.799$ & \multirow{2}{*}{$0.043^{*}$} \\
\hline & Not consumed & $74.09 \pm 5.905$ & & $75.18 \pm 5.090$ & & $73.00 \pm 6.595$ & \\
\hline \multirow[t]{2}{*}{ Eggs } & Consumed & $76.54 \pm 5.289$ & \multirow{2}{*}{$0.012^{*}$} & $77.42 \pm 5.196$ & \multirow{2}{*}{0.073} & $75.89 \pm 5.320$ & \multirow{2}{*}{0.072} \\
\hline & Not consumed & $72.94 \pm 5.641$ & & $73.63 \pm 5.423$ & & $72.40 \pm 6.041$ & \\
\hline \multirow[t]{2}{*}{ Seafood } & Consumed & $76.80 \pm 5.040$ & \multirow{2}{*}{0.076} & $76.55 \pm 5.365$ & \multirow{2}{*}{0.880} & $76.97 \pm 4.902$ & \multirow{2}{*}{$0.008^{*}$} \\
\hline & Not consumed & $74.80 \pm 5.875$ & & $76.81 \pm 5.546$ & & $73.05 \pm 5.691$ & \\
\hline \multirow[t]{2}{*}{ Sugary food } & Consumed & $75.69 \pm 5.420$ & \multirow{2}{*}{0.229} & $76.82 \pm 5.375$ & \multirow{2}{*}{0.478} & $74.83 \pm 5.345$ & \multirow{2}{*}{$0.039^{*}$} \\
\hline & Not consumed & $78.50 \pm 6.716$ & & $74.00 \pm 7.071$ & & $80.75 \pm 6.185$ & \\
\hline \multirow[t]{2}{*}{ Gripe water } & Consumed & $76.64 \pm 4.974$ & \multirow{2}{*}{$0.041^{*}$} & $76.88 \pm 5.885$ & \multirow{2}{*}{0.673} & $76.42 \pm 4.011$ & \multirow{2}{*}{$0.048^{*}$} \\
\hline & Not consumed & $74.17 \pm 6.298$ & & $76.00 \pm 3.240$ & & $73.38 \pm 7.152$ & \\
\hline \multirow[t]{2}{*}{ Thin porridge } & Consumed & $73.56 \pm 5.261$ & \multirow{2}{*}{$0.000^{*}$} & $74.94 \pm 4.683$ & \multirow{2}{*}{0.082} & $72.77 \pm 5.482$ & \multirow{2}{*}{$0.000^{\star}$} \\
\hline & Not consumed & $78.08 \pm 4.830$ & & $77.92 \pm 5.610$ & & $78.24 \pm 4.055$ & \\
\hline \multirow{2}{*}{ Clear broth } & Consumed & $75.57 \pm 5.105$ & \multirow{2}{*}{0.182} & $75.60 \pm 4.717$ & \multirow{2}{*}{$0.001^{*}$} & $75.55 \pm 5.420$ & \multirow{2}{*}{0.320} \\
\hline & Not consumed & $77.77 \pm 7.596$ & & $83.00 \pm 5.020$ & & $73.29 \pm 6.601$ & \\
\hline
\end{tabular}

\section{TABLE 6: Mean ( \pm SD) height (in $\mathrm{cm}$ ) of children aged 12-23 months based on the consumption of} each food item

*: indicates values that are statistically significant

Odds of above-average weight and height by the consumption of each food item was calculated by gender. The mean weight of male children who consumed meat was significantly higher when compared to those who did not $(\mathrm{OR}=6.533 ; \mathrm{p}=0.009)$. The mean weight of female children who consumed seafood was significantly higher when compared to those who did not $(\mathrm{OR}=4.154 ; \mathrm{P}=0.014)$. In terms of height, the mean height of male children who consumed peas $(\mathrm{OR}=7.438, \mathrm{P}=0.046)$ was significantly higher whereas the mean height of female children who consumed meat and were fed with gripe water $(O R=3.680, p=0.033, O R=3.23$, $\mathrm{p}=0.02$ ) was significantly higher as compared to those who did not. The other food items did not show any statistical significance with respect to increased weight or height.

\section{Discussion}

This study was mainly focused on establishing an association between infant and young child feeding practices and anthropometric measurements in an urban slum population in Bangalore, India. Although similar studies to demonstrate the association between feeding practices and nutritional status were done in rural areas, this UNICEF questionnaire was not used [14-16]. Further, our study provides detailed descriptive data regarding types of complementary food given to children in an urban slum population.

In this study, the male to female ratio is $0.74: 1$, with a female child preponderance. Hence, all analyses have been made according to gender and age. Our study did not reveal any statistical significance among the percentage of children in different age groups with respect to gender (Table 1).

In an economically and culturally diverse country such as India, differences in socioeconomic status, family structure, maternal education, and occupation can shed some light on infant and young child feeding practices [17]. Our study revealed that most families belonged to a nuclear family structure and to the upper lower socioeconomic category. In terms of maternal education, the majority of the mothers who were interviewed were housewives (86.4\%) and most mothers had studied up to a high school level, showing a significant statistical difference between the mothers of male and female children (Table 1 ). In a similar study with a female preponderance, half of their study population belonged to nuclear families and $91.8 \%$ of the mothers were housewives [15]. In another study conducted in Karnataka, it was observed that $51 \%$ of the population were from joint families and $49 \%$ nuclear families, but a majority of their study population belonged to the upper lower socioeconomic status group, similar to our study [18]. However, the primary 
focus of both these papers was on a rural population and studies focusing on urban slum populations in India are quite limited.

It is vital to understand the family structure, mother's occupation, and family socioeconomic status, as it directly has an effect on the nutritional status of infants and young children. In an urban slum population, nuclear families are predominant over extended families probably due to a limitation in space and housing facilities and the increased cost of living. This limits alternative childcare support, such as grandparents or cousins, especially needed for working parents, which is the case with nuclear families in lower socioeconomic groups. It has been observed that working mothers have reported difficulty in feeding their children notably by skipping breastfeeding or storing expressed milk, which in turn results in untimely feeds to the child. Furthermore, this study also notes that mothers find difficulty in cooking; thus increasing the likelihood of providing readymade food of poor nutritional value to their children. There also exists a lack of diversity of food items thus reducing net food intake by the child. Comparatively, mothers in extended families report ease in feeding their children, as they rely on siblings and other relatives. However, there exists a risk of untimely feeding practices and possible lack of knowledge of nutritious food choices [19].

In our study population, early initiation of breastfeeding was found to be more in males (56.1\%) as compared to females (45.5\%) (Table 3). The NFHS-4 fact sheet reports the early initiation of breastfeeding in the urban population as $42.8 \%$ and $53.7 \%$ for India and Karnataka [7,20]. Various studies have indicated a gender bias with respect to infant and young child feeding with male children being given more importance than females, more so in rural areas $[14,18,21-22]$. A total of $50 \%$ of the mothers reported a delay in the initiation of breastfeeding. However, only a small proportion delayed breastfeeding beyond three hours though results were not statistically significant. The most common reason for the delay was found to be due to cesarean section deliveries, followed by inadequate milk production (Table 3). In a similar study in South India, it was found that in $40.4 \%$ of the children, initiation of breastfeeding was within one hour of birth and $29.6 \%$ of mothers initiated feeding within the first four hours of birth. This study also lists reasons for the delay in the initiation of breastfeeding in descending order as maternal surgery (27.6\%), lack of milk production (21.5\%) and religious reasons (18.2\%). However, the study also did not show any statistical significance between the initiation of breast milk and gender [23].

In our study group, $84.6 \%, 50 \%$, and $14.3 \%$ of mothers at 12,18 , and 23 months respectively, continued breastfeeding. Possible reasons for discontinuing breastfeeding could be the cessation of milk production, lack of knowledge regarding the continuation of breastfeeding, and the ability of the child to quickly adjust to complementary food. However, two other studies showed the continuation of breastfeeding at one and two years of age as $99.7 \%$ and $87.2 \%$ and $88.1 \%$ and $73.1 \%$, respectively [16,24]. In order to improve the nutritional status of our children, it is essential to create awareness among mothers regarding the advantages of continued breastfeeding particularly in lower socioeconomic groups [25].

The proportion of urban slum children who were fed with a bottle was $40.6 \%$ whereas it was $51.9 \%$ in the 21 23 months age group. Studies in various states of India such as Karnataka, Jammu and Kashmir, and Punjab show similar proportions of bottle feeding: $49.4 \%, 51.5 \%$, and $63.3 \%$, respectively [16,26-27].

The MGRS [13] was designed to provide a single international standard by the collection of anthropometric data from children representative of various ethnic backgrounds and socioeconomic status and, hence, was used to assess our subjects as well. The graphs that were generated in comparison with the MGRS population showed that the mean $\mathrm{Z}$ scores for all anthropometric measurements in our subjects were less than that of the standard (Figure 1). Since racial, ethnic, and socioeconomic differences have been addressed in the MGRS, nutrition is probably responsible for such low means in our study population. This further reinforces the fact that early initiation of breastfeeding, continued breastfeeding, and adequate complementary feeding can, in fact, result in better nutritional outcomes evidenced by better mean anthropometric parameters.

In our study, we found that $16.7 \%$ were wasted, out of which $4.2 \%$ were severely wasted (below $-3 \mathrm{SD}$ ), $50 \%$ stunted, and $26 \%$ underweight. The NFHS - 4 for India reports $20.0 \%$ wasted out of which $7.5 \%$ were severely wasted, $31.0 \%$ stunted, and $29.1 \%$ underweight in children below five years of age [7]. Similarly, statistics from the Karnataka fact sheet shows $24.8 \%$ wasted out of which $9.7 \%$ were severely wasted, $32.6 \%$ stunted, and $31.5 \%$ underweight in children below five years of age [20].

An attempt at formulating an association between the type of complementary food consumed and each anthropometric measurement was made and a positive impact on the weight and height parameters were observed, particularly with some food items, such as meat, eggs, seafood, thin porridge, with certain results showing statistical significance (Tables 5-6). Most studies have analyzed the consumption of various complementary food items independent of the anthropometric measurements of their study population and thus have not been able to show a direct association between the two [24,26,28-29]. In our study, we have compared the proportion of food consumption with height and weight as a 1:1 comparison, unlike previous studies. It can, however, be argued that the exact quantity of food consumed was not taken into consideration, the lack of which limits in-depth understanding of IYCF, which can be implemented in future studies for a precise analysis. 
Gripe water consumption and its effect on the nutritional status of a child has always been a controversial topic of discussion and was addressed in this study. It was found that the height and weight of the total population were significantly higher in those children who consumed gripe water as compared to those who did not $(\mathrm{p}=0.041, \mathrm{p}=0.054)$. Gripe water is most commonly used as a pre-lacteal feed in most children, but in our study, we found that mothers went on to give their children gripe water along with complementary feeding. The most common reasons for using gripe water was to aid in digestion, insistence by elders, and to relieve abdominal colic though studies have shown that gripe water, in fact, has resulted in an increase in constipation, infantile colic, fevers, cough and cold, and diarrhea [30].

The urban slum undertaken in this study is part of the field practice area of our teaching hospital, which made it easier for the investigators to establish a good rapport with its residents. Most studies with similar objectives were conducted in a rural population and indigenously designed questionnaires were used. In our study, we utilized the UNICEF IYCF questionnaire in an urban slum population. Meticulous collection of data was achieved by using random sampling of CEBs for minimizing the selection bias and rephrasing questions to reduce the recall and information bias. This study is distinct from other studies in terms of comparing the consumption of complementary food with anthropometric measurements to show a possible direct cause-effect relationship, unlike other studies that have studied the same parameters independently.

Even though the latest NFHS fact sheets were taken into consideration while calculating the required sample size, our sample size was small. Larger sample size would help in demonstrating stronger associations between IYCF and anthropometry. In terms of study design, a follow-up study would have been more robust with respect to reducing the recall bias, measurement bias by inquiring and verifying the quantity of food given, interval anthropometric measurements, and information regarding illnesses if occurred during the study period that could alter feeding and anthropometry. The survey lacks questions on the duration of exclusive breastfeeding and age at initiation of complementary feeds required for an in-depth understanding of IYCF. The effect of gripe water on the anthropometric measurements of infants and young children needs to be further studied.

\section{Conclusions}

Infant and young child feeding practices are one of the most commonly studied aspects of maternal knowledge of child nutrition, yet many countries still observe a significant amount of malnutrition and ill health among its children. Knowledge regarding feeding practices, commencing from the initiation of breastfeeding to complementary feeding, especially during the early growing years, is vital to overall child development. In this study, we have also addressed the importance of the continuation of breastfeeding for up to two years of age and this must be advocated to families at primary health care centers and health camps. An attempt to understand the correlation between basic food items and anthropometry was also done in this study, which revealed the necessity of further such correlation studies. This, in our opinion, would help social workers and health care professionals alike to guide families in raising strong and healthy children. In the long term, this will prove beneficial to not only the community but eventually overall national development as well.

\section{Additional Information \\ Disclosures}

Human subjects: Consent was obtained by all participants in this study. M S Ramaiah Medical College Ethics Committee issued approval ECR/215/Inst/KA/2013/RR-16. The above mentioned academic protocol was placed before the ethics committee in the meeting held on 23rd June, 2017 and the same was approved by the ethics committee. The study has been approved to be conducted for a period of 1 year. The ethics committee expects to be informed about: - any adverse event occurring in the course of the study, - any amendments to the protocol, change of study procedure, site/investigator and premature termination of the study with reason along with summary and, - progress of the study, interim reports and final reports to be given at 6 months from the date of approval of the study. Kindly note that a copy of the consent document to be given to the study participant giving the consent and the members of Ethics Committee have rights to monitor the trail with prior intimation. Animal subjects: All authors have confirmed that this study did not involve animal subjects or tissue. Conflicts of interest: In compliance with the ICMJE uniform disclosure form, all authors declare the following: Payment/services info: All authors have declared that no financial support was received from any organization for the submitted work. Financial relationships: All authors have declared that they have no financial relationships at present or within the previous three years with any organizations that might have an interest in the submitted work. Other relationships: All authors have declared that there are no other relationships or activities that could appear to have influenced the submitted work.

\section{References}

1. World Health Organization: Infant and Young Child Feeding: Model Chapter for Textbooks for Medical Students and Allied Health Professionals. The Importance of Infant and Young Child Feeding and Recommended Practices. WHO, Geneva; 2009.

2. Martin RM, Smith GD, Frankel S, Gunnell D: Parents growth in childhood and the birth weight of their 
offspring. Epidemiology. 2004, 15:308-316. 10.1097/01.ede.0000120042.16363.e3

3. Indicators for assessing infant and young child feeding practices: part 1: definitions . (2007). Accessed: May 2017: https://apps.who.int/iris/bitstream/handle/10665/43895/9789241596664_eng.pdf?sequence=1.

4. Victora CG, Bahl R, Barros AJ, et al.: Breastfeeding in the 21st century: epidemiology, mechanisms, and lifelong effect. Lancet. 2016, 5:475-490. 10.1016/s0140-6736(15)01024-7

5. Cai X, Wardlaw T, Brown DW: Global trends in exclusive breastfeeding. Int Breastfeed J. 2012, 7:12. 10.1186/1746-4358-7-12

6. Global nutrition targets 2025. Breastfeeding policy brief . (2014). Accessed: May 2017: https://apps.who.int/iris/bitstream/handle/10665/149022/WHO_NMH_NHD_14.7_eng.pdf?ua=1.

7. National Family Health Survey -4, India fact sheet. (2015-2016). Accessed: May 2017: http://rchiips.org/nfhs/pdf/NFHS4/India.pdf.

8. Victora CG, Horta BL, de Mola CL, et al.: Association between breastfeeding and intelligence, educational attainment, and income at 30 years of age: a prospective birth cohort study from Brazil. Lancet Glob Health. 2015, 30:199-205. 10.1016/S2214-109X(15)70002-1

9. Horta BL, Bahl R, Martinés JC, Victora CG: Evidence on the long-term effects of breastfeeding: systematic review and meta-analyses. World Health Organisation, Geneva; 2007.

10. Lamberti LM, Zakarija-Grković I, Walker CL, Theodoratou E, Nair H, Campbell H, Black RE: Breastfeeding for reducing the risk of pneumonia morbidity and mortality in children under two: a systematic literature review and meta-analysis. BMC Public Health. 2013, 13:18. 10.1186/1471-2458-13-S3-S18

11. WHO, UNICEF, USAID, AED, UCDAVIS, IFPRI: World Health Organization. Indicators for Assessing Infant and Young Child Feeding Practices, Part 2: Measurement. WHO, Geneva; 2010.

12. Singh T, Sharma S, Nagesh S: Socio-economic status scales updated for 2017. Int J Res Med Sci. 2017, 24:3264-3267. 10.18203/2320-6012.ijrms20173029

13. De Onis M, Garza C, Victora CG, Onyango AW, Frongillo EA, Martines J: The WHO Multicentre Growth Reference Study: planning, study design, and methodology. Food Nutr Bull. 2004, 25:15-26. 10.1177/15648265040251S104

14. Shashank KJ, Chethan TK: A study on breastfeeding practices among mothers in rural area of Mangalore district: a cross-sectional study. Ntl J Community Med. 2016, 7:134-137.

15. Saizuddin M, Hasan MS: Infant and young child feeding (IYCF) practices by rural mothers of Bangladesh . J Natl Inst Neurosci Bangladesh. 2016, 2:19-25. 10.3329/jninb.v2i1.32958

16. Banapurmath CR, Nagaraj MC, Banapurmath S, Kesaree N: Breastfeeding practices in villages of central Karnataka. Indian Pediatr. 1996, 1:477-479.

17. Islam MA, Rahman MM, Mahalanabis D: Maternal and socioeconomic factors and the risk of severe malnutrition in a child: a case-control study. Eur J Clin Nutr. 1994, 48:416-424.

18. Angadi MM, Jawaregowda SK: Gender discrimination in relation to breast feeding practices in rural areas of Bijapur district, Karnataka. Int J Contemp Pediatr. 2015, 4:340-344. 10.18203/2349-3291.ijcp20150970

19. Kabir A, Maitrot MRL: Factors influencing feeding practices of extreme poor infants and young children in families of working mothers in Dhaka slums: a qualitative study. PLoS One. 2017, 12:1-15. 10.1371/journal.pone.0172119

20. National Family Health Survey - 4, Karnataka fact sheet . (2015-2016). Accessed: May 2017: http://rchiips.org/nfhs/pdf/NFHS4/KA_FactSheet.pdf.

21. Basu S, Aundhakar CD, Galgali A: Gender discrimination in relation to exclusive breast feeding practices amongst twins in rural India. Int J Health Sci Res. 2014, 4:139-143.

22. Sohag AA, Memon S: Perception practices and factors associated with exclusive breast feeding failure . Med Channel. 2011, 17:100-102.

23. Swetha R, Ravikumar J, Rao RN: Study of breastfeeding practices in coastal region of South India: a cross sectional study. Int J Contemp Pediatr. 2017, 6:74-78. 10.5455/2349-3291.ijcp20140812

24. Aguayo VM: Complementary feeding practices for infants and young children in South Asia. A review of evidence for action post-2015. Matern Child Nutr. 2017, 13:e12439. 10.1111/mcn.12439

25. Rollins NC, Bhandari N, Hajeebhoy N, et al.: Why invest, and what it will take to improve breastfeeding practices?. Lancet. 2016, 30:491-504. 10.1016/s0140-6736(15)01044-2

26. Sangra S, Kumar D, Dewan D, Sangra A: Reporting of core and optional indicators of infant and young child feeding practices using standardized WHO formats from a rural population of Jammu region. Int J Med Sci Public Health. 2017, 6:1603-1610. 10.5455/ijmsph.2017.0824721092017

27. Chattha MN, Mazhar I, Ahmad S, Latif A, Rai ME: Breast feeding knowledge and practices in Sialkot . Pak J Med Health Sci. 2016, 10:1272-1275.

28. Korday CS, Sharma RK, Malik S: Assessment of nutritional status in children using WHO IYCF indicators: an institution based study. Int J Contemp Pediatr. 2018, 5:783-790. 10.18203/2349-3291.ijcp20181412

29. Syed S, Das B: Assessment of nutritional status and its association with feeding practices in children under five years. Int J Contemp Pediatr. 2017, 4:68-72. 10.18203/2349-3291.ijcp20164438

30. Jain K, Gunasekaran D, Venkatesh C, Soundararajan P: Gripe water administration in infants 1-6 months of age - a cross-sectional study. J Clin Diagn Res. 2015, 9:6-8. 10.7860/JCDR/2015/13727.6738 